Article

\title{
Social Media Influencer's Reputation: Developing and Validating a Multidimensional Scale
}

\author{
Eun Ah Ryu (1) and EunKyoung Han * \\ Department of Media and Communication, Sungkyunkwan University, Seoul 03063, Korea; earyu76@gmail.com \\ * Correspondence: bird24@skku.edu
}

check for updates

Citation: Ryu, E.A.; Han, E. Social Media Influencer's Reputation: Developing and Validating a Multidimensional Scale. Sustainability 2021, 13, 631. https://doi.org/ $10.3390 /$ su13020631

Received: 18 December 2020 Accepted: 7 January 2021 Published: 11 January 2021

Publisher's Note: MDPI stays neutral with regard to jurisdictional clai$\mathrm{ms}$ in published maps and institutional affiliations.

Copyright: $(\odot 2021$ by the authors. Licensee MDPI, Basel, Switzerland. This article is an open access article distributed under the terms and conditions of the Creative Commons Attribution (CC BY) license (https:// creativecommons.org/licenses/by/ $4.0 /)$.

\begin{abstract}
Since the introduction of smartphones in 2009, social networking services (SNS), which have seen a surge in users, facilitated changes in the media environment along with social influence that has increased the economic value and political influence of SNS. In particular, as consumers' media use and consumption behavior change around digital media, social media plays a very important role in consumers' lives. From this perspective, influencers who influence not only consumers' consumption behavior, but also decision-making and opinion formation based on social media are attracting attention. Therefore, the aim of this study was to develop items to measure an influencer's reputation as a new source of information in the SNS environment; no previous researchers have presented generalized measurement items for an influencer's reputation. We intended to identify what dimensions and items in the existing literature could effectively measure a social media influencer's reputation and to verify each item's relevance as a measure of a social media influencer's reputation. Based on in-depth interviews with 30 experts and empirical findings from 557 adults, this study identified dimensions that impact on a consumer's perception of a social media influencer and developed a scale. The results showed that the social media Influencer's Reputation scale comprises four distinctive dimensions: Communication skills, influence, authenticity, and expertise. Additionally, the reliability and validity of the scale were assessed, using exploratory and confirmatory analyses and construct validity. The findings confirmed that the social media influencer's reputation scale measurement items, in this study, can be used as a consistent measurement tool for each dimension. It is also important to develop value in favor of the marketing strategy by increasing value through the influencer's reputation.
\end{abstract}

Keywords: social media; influencer; reputation; communication skills; influence; authenticity; expertise

\section{Introduction}

In recent years, many companies have utilized social media influencers as their marketing strategy to broaden their contact points with and empathize with consumers. Especially for millennials - the first all-digital generation - they prefer to communicate through mobile messages and SNS channels [1], and the use of social media influencers has greatly increased as a marketing strategy. In one survey, the global market for influencer marketing was approximately $\$ 2$ billion as of 2017 and was expected to grow to $\$ 50-110$ billion by $2020[2,3]$. The Korean social media influencer market was also expected to reach two trillion won by 2020, up from 400 billion won in 2017 [4].

An influencer is a person who has hundreds of thousands or millions of followers on social media platforms, such as YouTube, Instagram, and Facebook [5-9]. Online social networks allow influencers to share their life with consumers, create and interact with large amounts of multimedia content, and complement feedback and comments [10]. Due to their social network-based familiarity and followers, they exercise enormous influence. In the digital media environment, one major role of influencers is to drive consumer decision-making on purchasing behavior. The best example of the effect of influencers is American teen icon Kylie Jenner, a young influencer with 100 million Instagram followers 
and 25 million Twitter followers. She launched Kylie Cosmetics in 2015 and in 2016 and has posted $\$ 630$ million in sales. She became worth approximately 1 trillion won at age 21, and Forbes anointed her the world's youngest billionaire in 2018. Even now, Kylie Jenner not only has her own brand, but has also expanded her influence into modeling, broadcasting, and other businesses [11].

Influencers give consumers familiarity and consumers grant them credibility because they are sharing their own experiences and lifestyles [12-16]. Influencers also affect consumer decision making, opinions, attitudes, and behaviors [17], and thus, using them in marketing is considered a more effective strategy than many others [18-20]. In particular, because research indicates that influencers affect potential customers [21-25], companies are utilizing influencers as part of their marketing strategies, as well as incorporating them into business models by directly engaging them in content production [26-28]. However, a darker side of influencers has emerged as their numbers and activities have spread. Influencers have been embroiled in controversy over consumer deception, violations of law, and sharing false information including faking follower numbers, and these controversies have had a negative impact on influencer credibility, as well as on individual influencers' reputations [11].

Reputation is an evaluation that reflects stakeholders' beliefs about or perceptions of an entity's nature, behavior, etc., accumulated from the past to the present [29-32]. It encompasses consistent and comprehensive assessments accumulated over time, and a positive reputation serves as a buffer in times of crisis [31,33,34]. Reputation also positively influences both financial and customer variables such as consumer confidence and loyalty. Given that a good reputation has a competitive advantage and attracts more people, it is considered an important factor for achieving success [29-34]. In this context, influencers should build a positive and favorable reputation from consumers to maintain their own value and strategically manage their personal reputation evaluated by consumers.

Therefore, this study aimed to establish a broad index of an influencer's reputation and to identify and investigate the efficacy of a social media influencer's reputation as an effective marketing and communications tool. Recently, social networking services (SNS) have provided consumers with real-time access to influencer content and broader information about them; this means that it has become easier than ever before for consumers to evaluate individuals and organizations. In this context, a favorable reputation is thus expected to help consumers realize which social media influencer has content associated with integrity and credibility. Therefore, an influencer's success relies on a positive and favorable reputation with consumers, and reputation management is expected to contribute significantly to the sustainability of influencer marketing.

However, most researchers limit studies on marketing and advertising's effects to certain areas. Recent scholars have examined the relationship between influencer attributes and marketing and advertising's effect, but they regrettably limited their study to only some characteristics and properties [7,8,35-39].

The purpose of this study was to examine the characteristics of social media influencers' reputations as a constituent concept by examining the factors structure of reputation. In other words, we want to understand what sub-dimensional concept the social media influencer's reputation constitutes and to see what measurement items this sub-dimensional concept can be measured by. In addition, through the process of developing a measure of the influencer's reputation, it is intended to verify the validity of the manipulation of the social media influencer's reputation as a constituent concept. This study attempted to conceptualize the composition of the social media influencer's reputation and aimed to lay the foundation for empirical research on influencers' reputations.

\section{Literature Review}

\subsection{Concept of an Influencer's Reputation}

Influencers influence not only their followers but also the public [17,40], but different from entertainers, they are ordinary people who have no public personas despite their 
influence [41]. Beginning with online power bloggers, the influencer concept expanded to social media as the scope of content expanded across a broadening range of online platforms [42]. As social networking sites meet new relational functions that traditional media cannot, influencers can reach broad numbers of consumers through communication and relationship building [43]. In previous studies, $49 \%$ of consumers relied on influencer recommendations [44], and influencers affected potential customers' attitudes and behaviors $[45,46]$. In addition, influencers have been shown to have a brand-building effect by creating positive online word of mouth, and were, in fact, shown to be more reliable than more traditional brand marketing $[7,8,47]$. In a Korean study, influencer trustworthiness and expertise showed a positive effect on consumers' behavior [48], and in a different study, influencers' product descriptions and analyses had a large impact on consumers' product evaluations [49]. Influencers' reach has expanded into fields as varied as society, culture, and the economy, and as their influence grows, they need to take responsibility for their actions and strive to manage their reputations to maintain and improve value to the customer.

Reputation is an overall assessment of an entity's image, and as a consistent and comprehensive assessment, accumulated over a long period of time, rather than just an impromptu judgment, reputation is considered a company's most valuable intangible asset $[33,50,51]$. Indeed, it is a socially structured recognition system that creates strong rewards for good behavior and is recognized as an important factor in improving value for both individuals and groups [52-56]. A favorable reputation not only creates real value, but also protects against crises. As such, maintaining an advantage requires reputation management.

Previous researchers have mainly studied personal reputation among CEOs, politicians, entertainers, and athletes and organizational reputation in economics, organizational studies, and marketing. Recently, reputation research has been expanding into various areas such as brand, cities, and countries [31,50,57-60]. A personal reputation is a collection of perceptions that others have toward a particular individual, formed from unique characteristics and behaviors, long-established images, and others' impressions [35,61,62]. For instance, Carter, Bitting, and Ghorbani found that the public's assessment of an actor's performance in a role determines the actor's positive or negative reputation [63]. Rein defined personal reputation as being fundamentally intertwined with other reputational objects [53], while Miller conceptualized it as a judgment of a person's past behavior, which is used to predict future behavior [55].

With the expansion of SNS into everyday life, an influencer's reputation for creating as much value in various areas, such as CEOs and celebrities do, has become more important. Based on these discussions, we expect that in the future, an influencer's reputation will continue to elicit from consumers, not only expectations, but also activities that can generate social and economic value. In that context, we defined the concept of social media influencer's reputation as consumers' perceptions and evaluations of influencers' various activities and images acquired through direct and indirect experience. Our study goal against this backdrop was to study social media influencers' reputations by applying criteria that were primarily applied in existing celebrity and CEO studies to derive objective criteria for evaluating influencers.

\subsection{Components of an Influencer's Reputation}

As social media use has become more common, celebrity reputations are becoming more important in the media environment where personal information can be checked and shared in real-time. In a prior study, reputation was not constructed by a single dimension, but was multidimensional and reflected influencing factors that expressed the overall characteristics of an object, including an image $[53,57,64]$. Therefore, it is necessary to take a comprehensive look at the concepts of celebrity attributes, images, and personal reputation. 


\subsubsection{Celebrity Attributes and Image Components}

Existing researchers have studied and classified celebrity attributes. McGuire divided the attributes of celebrities into familiarity, preference, and similarity [65], and Ohanian identified credibility, truthfulness, expertise, and attractiveness [66]. Belch and Belch presented expertise, credibility, and attractiveness as celebrity attributes [67], while Erdogan, Baker, and Tag presented credibility, expertise, familiarity, similarity, and likability [68].

In general, credibility and attractiveness have been identified celebrity attributes [66,69]. Credibility refers to expert knowledge, ability, and intention to make a valid argument on a particular subject and includes expertise and trustworthiness [70-72], and attractiveness means how familiar, likes, and similar information sources are to be perceived as being similar to themselves including familiarity, likability, and similarity [65,71,73-75]. In general, credibility and attractiveness affect the likelihood that consumers will accept a message, namely, through persuasion [65]. A particularly attractive celebrity in an advertisement can induce consumer interest in a product or brand [76] and strengthen consumer identification through increased purchases [77,78], and beyond affecting consumer behavior, attractiveness has been regarded as a fundamental factor in the formation of interpersonal relationships [79].

In addition to celebrity attributes, image is a factor for an influencer's reputation. Previous studies have shown that a celebrity's positive image can change negative perceptions and affect credibility [80], and many others have shown that a CEO's image plays an important role in determining a company's image. Garbet argued that a CEO's image helps to establish the individuality of a company, and Gaines-Ross argued that a CEO's image has a positive impact on marketing a company to consumers and investors [81,82].

Image is critical, not only for CEOs, but also for entertainers, who among other characteristics, build awareness and influence the public. Han Eun Kyung and Yoo Jae Ha presented nine items to measure the image of Korean Hallyu stars such as price, value, advertising, quality, benefits, guarantees, and similarities; the price and value dimensions related to whether Hallyu stars were able to gain a large amount of attention, advertising related to whether the dimensions were being promoted through proper media exposure, benefits and guarantee related to whether dimensions provided spiritual pleasure, and similarity related to whether the dimensions promoted feelings of cultural ties, familiarity, and homogeneity [83]. Oh Yoon Kyung and Lee Kyung Hee measured the style type and image of Korean female entertainers and identified four dimensions of image, vivacity, attractiveness, extroversion, and familiarity, that were measured with 21 sub-items. However, the author identified as a limitation the fact that the components were limited to their appearance and thus could not be used to assess activities or performance [84]. This can be understood as a limitation in that celebrity is a multidimensional concept that comprises various attributes including trustworthiness, expertise, likability, and similarity $[71,73,85]$.

Therefore, for this study, we needed to look, not only at the image properties of celebrities, but also at existing studies on the components of celebrity reputation. Based on the celebrity attributes and image components presented in previous studies, we sought to extract primary influencers' evaluation criteria and derive components and measurement items that would reflect the characteristics inherent in an influencer's reputation through expert interviews and consumer surveys.

\subsubsection{Celebrity Reputation Components}

Various fields, including marketing, management, communication, and psychology, are contributing to the burgeoning literature on reputation. Some researchers have conceptualized and measured reputation in a unidimensional way, but the prevailing view is that reputation is a multidimensional construct, reflecting unique and diverse aspects in which individual viewers base their reputational judgement. Scholars' views of the dimensionality of the reputation construct have evolved over time and have employed different terminologies and classifications. 
Research on personal reputation has centered around chief executive officers and principal communicators of companies [86,87]. CEOs establish strategic plans throughout a company's operations and carry out management activities [88], and they are the best executors and final decision-makers for all activities undertaken by the company [89]. Consequently, CEO reputation is established over time, and built through long-term and planned management [81].

The most representative study on CEO reputation is by Burson-Marsteller, who surveyed stakeholders and CEOs for components of CEO reputation. The CEOs in that study chose reliability, communication skills, stable corporate management skills, ethical behavior, and crisis management skills, and the stakeholders chose reliability, clear vision, ability to recruit and maintain talented people, ability to manage customers, ability to manage crises, and ability to think globally [90]. In another study, Han Eun Kyung reconstructed Burson-Masteller's CEO reputation dimensions to suit Korean characteristics and identified six dimensions in CEO reputation in Korea: Reliability, strategic vision, customer management ability, personnel management ability, crisis management ability, and Korean dignity [91].

In the field of sports, athletes' reputational components have also been studied. Ahn Jae Han identified six features of a Korean athlete's reputation: Personal character, performance, external appeal, privacy, sportsmanship, and capacity management. Among them, sportsmanship appeared to be the most important: Players' attitudes had more impact on their reputations than did their actual results [92]. In entertainer reputation literature, Lee Bo Young studied the components of reputation for Korean entertainers and identified seven items: expertise, attractiveness, personal character and image, morality, privacy management, crisis management, and social responsibility [93]. Han Eun Kyung, Lee Bo Young, and Moon Hyo Jin measured Korean entertainer's reputation in three Asian countries: Korea, China, and Singapore. They also derived seven reputation components, with 21 attributes: external characteristics, expertise, individual personalities, privacy management, crisis management, internal and external relations, and social contribution. The authors did identify significant differences among the three countries in the perceived importance of expertise, external characteristics, and individual personality dimensions in an entertainer's reputation [56]. The above studies reflect the multidimensional nature of celebrity reputation, and based on these findings, we determined that an influencer's reputation would also comprise multiple components.

Personal reputation research, which has been conducted mainly on CEO reputation, has been expanding into various other populations, such as entertainers and athletes. As the existing media communication environment changes rapidly around SNS, the influence of personal reputation will become more important in the future. Therefore, as part of the ongoing research on reputation, we focused on personal reputation as opposed to company and organization reputational research that has more typically been the focus of reputation studies. There is no doubt that the recent growing influence of influencers on consumers, companies, and society has much to do with celebrities' and CEOs' influence on societies. Therefore, with this study we sought to derive reputation components that reflected the characteristics of influencers based on the components of celebrity and CEO reputations. No prior studies have presented influencer's reputation components. Therefore, we intended to identify what dimensions and items in the existing literature could effectively measure social media influencers' reputations and to verify each item's relevance as a measure of a social media influencer's reputation. Through our efforts, we aimed to answer the following research questions.

Research Question 1. What dimensions and items does the social media influencer's reputation consist?

Research Question 2. What are the convergence validity and discriminant validity of the social media influencer's reputation dimensions? 


\section{Research Methods}

\subsection{Sampling Procedure and Sample}

This study was designed to develop a measure of celebrity reputation and attempt to identify key dimensions for evaluating diverse components of social media influencers' reputations.

We divided this study into preliminary and main surveys. The purpose of the presurvey was to extract the necessary components for measuring social media influencers' reputations. To that end, we conducted a Delphi technique on 30 experts during the initial stage of extracting items. The composition of the experts was marketing and social media professionals in their 20s to their 50s in Korea; by gender, there were 16 men and 14 women.

Next, we conducted the main survey in two rounds to verify the reliability and validity of the social media influencer's reputation components and measurement items. We sampled Korean social media users with experience as influencers through an online survey. There were 269 respondents to the first survey and 288 respondents to the second.

For survey 1, $137(50.9 \%)$ of the respondents were men and $132(49.1 \%)$ were women. By age, $84(31.2 \%)$ of the respondents were aged 20-29, followed by those aged 30-39 $(78,29 \%), 40-49(55,20.4 \%)$, and 50-59 (52, 19.3\%). Survey 2 had $148(51.4 \%)$ male respondents, and $140(48.6 \%)$ respondents were women. By age, $78(27.1 \%)$ of the respondents were aged 20-29, followed by those aged 30-39 (92, 31.9\%), 40-59 (59, 20.5\%), and 50-59 $(59,20.5 \%)$. The demographic profiles of the respondents are presented in Table 1.

Table 1. Demographic profiles for the sample.

\begin{tabular}{|c|c|c|c|c|c|}
\hline \multirow{2}{*}{\multicolumn{2}{|c|}{ Characteristics }} & \multicolumn{2}{|c|}{ Survey 1} & \multicolumn{2}{|c|}{ Survey 2} \\
\hline & & $\begin{array}{l}\text { Frequency } \\
(N=269)\end{array}$ & $\%(100)$ & $\begin{array}{l}\text { Frequency } \\
(N=288)\end{array}$ & $\%(100)$ \\
\hline \multirow{2}{*}{ Gender } & Male & 137 & 50.9 & 148 & 51.4 \\
\hline & Female & 132 & 49.1 & 140 & 48.6 \\
\hline \multirow{4}{*}{ Age } & $20-29$ & 84 & 31.2 & 78 & 27.1 \\
\hline & $30-39$ & 78 & 29.0 & 92 & 31.9 \\
\hline & $40-49$ & 55 & 20.4 & 59 & 20.5 \\
\hline & $50-59$ & 52 & 19.3 & 59 & 20.5 \\
\hline \multirow{3}{*}{$\begin{array}{l}\text { Educational } \\
\text { Level }\end{array}$} & Below or high school & 48 & 17.8 & 44 & 15.3 \\
\hline & University & 192 & 71.4 & 213 & 74 \\
\hline & Graduate school or higher & 29 & 10.8 & 31 & 10.8 \\
\hline
\end{tabular}

\subsection{Procedure}

For this study, we conducted expert interviews and administered a consumer survey to determine the existing scale development process and proceed with the work of refining and embodying the items extracted from the literature.

\subsubsection{Expert Interviews}

We first looked at prior studies related to the images, attributes, and reputations of individuals, such as entertainers, athletes, and CEOs. We, then, conducted the Delphi technique with 30 experts from 25 May to 10 June 2019. The Delphi technique is a research method that systematically extracts expert opinions to predict the future and statistically analyzes the results to draw conclusions. This technique gathers expert knowledge on the subject during a structured group communication process in which decisions are made several times until consensus is reached. In this study, the Delphi technique was performed as a preliminary study to accurately predict whether or not a paradigm shift in marketing strategy will occur when the influence of influencers spreads. This study was conducted three times with 30 academic and practical experts. Open questions and expert interviews led to 133 initial items for measuring social media influencers' reputations. The interviews included 30 experts composed of marketers (15), professors (5), and heavy influencer 
users (10) who watch social media influencer content. They were asked to respond to the following statement: "Please provide a brief description of the social media influencers' characteristics and activities that you would associate with the words 'good reputation' or 'bad reputation'. Please be specific in providing personality, activities, and behaviors you would consider reflective of social media Influencers' Reputation." The purpose of the expert interviews was to uncover specific characteristics of reputation that experts generally think of for social media influencers in their professional and life experiences.

Two faculty and two Ph.D. students in the field of communication reevaluated these 133 items in terms of their similarity, repetitiveness, and importance, leaving 72 items. To purify the measurement tool on the basis of its psychometric properties, 30 experts who had joined the expert interview were re-invited and rated the extent to which 72 items were appropriate for the social media Influencer's Reputation scale on 7point Likert scales ( 1 = Strongly disagree, $7=$ Strongly agree). While assessing the items, they were asked to indicate items appearing identical and repetitive from the list and to suggest any other important and considerable items to be further included in the scale. Items below 4.5 points out of the 7 in terms of appropriateness were eliminated. Those reported as being repeated and identical items by at least five experts were also eliminated regardless of their appropriateness scores, resulting in 66 items.

In the following survey, 30 experts were re-invited and shown the 66 items along with their average points earned in the previous stage. They were then asked to indicate their agreement with the "scores of the item" on 7point Likert scales. Items were dropped in case (1) its coefficient of variance (CV) was higher than 0.3 or (2) the item negatively influenced the internal consistency on the basis of the Cronbach alpha scores. This process eliminated 23 additional items, leaving 43 items.

\subsubsection{Consumer Survey}

We conducted the survey with an initial group of consumers aged 20 to 59 who were recruited through an online survey company to verify the reliability and validity of the social media influencer's reputation components and measurement items.

Through an online survey, we distributed 300 surveys with 43 social media influencer's reputation measurement items from 4-8 July 2019. From the 300 questionnaires, we used a total of 269 for analysis, excluding surveys with insincere responses from the surveys that were returned. Next, we performed exploratory factor analysis (EFA) and reliability analysis to identify the factor structure for a particular concept, find measurement items with high correlation between them, and bind them as common factors. Through this, we identified the structure of the social media influencer's reputation components and measurement items.

After the first survey, we refined the questions to eliminate some, leaving 37 items for study. For the second survey, 300 consumers were surveyed from 15-19 July 2019, and we used data from 288 completed questionnaires for our analyses. We conducted confirmatory factor analysis (CFA) to examine the validity of the measured items purified in the first test (see Table 2).

\subsection{Measure}

For this study, we defined a social media influencer's reputation as consumers' recognition and evaluation of influencers' various activities and images based on direct and indirect experience. The social media influencer's reputation items we derived were rated on 7 point Likert scales ( 1 = Strongly disagree and 7 = Strongly agree), and to verify the reliability and validity of the measurement items, we performed descriptive statistics, reliability analysis, correlation analysis, EFA, and CFA. We analyzed the data we collected for this study using SPSS 23.0 and AMOS 23.0. 
Table 2. Research procedure.

\begin{tabular}{ccc}
\hline & Items & Description \\
\hline \multirow{2}{*}{ Delphi Technique } & Literature Review & Item Generation \\
\cline { 2 - 3 } & Open questions & Item Purification \\
\cline { 2 - 3 } & Expert Interviews & Item Refinement \\
\hline Presurvey & Consumer Surveys & Scale Development \\
\hline Main Survey & Validation & $\begin{array}{c}\text { EFA, Reliability analysis, CFA, } \\
\text { Validity analysis }\end{array}$ \\
\hline
\end{tabular}

Note: Exploratory factor analysis: EFA; confirmatory factor analysis: CFA.

\section{Results}

\subsection{Exploratory Factorial Analysis}

In the reliability analysis, the Cronbach's $\alpha$ for the 43 measurement items was greater than 0.70, confirming internal consistency [94]. EFA then determined the factor structure for the items; for factor extraction, we used a maximum likelihood model, and the factor rotation used oblique rotation. Based on an eigenvalue of 1 , factor loading was only selected for significant items greater than 0.40 [95,96]. The Kaiser-Meyer-Olkin (KMO) value was high at 0.97 , and Bartlett's test results showed a significant probability of 0.000 , indicating that the data were suitable for factor analysis.

Table 3 presents the EFA results for the social media influencer's reputation components. The final 34 items were extracted by removing items with a factor load of 0.40 or less or that were cross-loading and compromising reliability, and four extracted factors accounted for $63.02 \%$ of the total variance: Communication skills, influence, authenticity, and expertise.

Table 3. Exploratory factor analysis of social media influencer's reputation components.

\begin{tabular}{|c|c|c|c|c|}
\hline \multirow{2}{*}{ Variable } & \multicolumn{4}{|c|}{ Factor } \\
\hline & (1) F1 & (2) F2 & (3) F3 & (4) F4 \\
\hline $\begin{array}{c}\text { Influencers do not hesitate to accept and experience } \\
\text { something new. }\end{array}$ & 0.704 & & & \\
\hline $\begin{array}{l}\text { Influencers well explain the relationship between content, } \\
\text { product, and brand. }\end{array}$ & 0.689 & & & \\
\hline Influencers actively communicate with consumers. & 0.664 & & & \\
\hline $\begin{array}{l}\text { Influencers clearly communicate information about a } \\
\text { product or brand. }\end{array}$ & 0.549 & & & \\
\hline $\begin{array}{l}\text { Influencers know and understand a product or } \\
\text { brand well. }\end{array}$ & 0.521 & & & \\
\hline Influencers have a confident attitude. & 0.499 & & & \\
\hline $\begin{array}{l}\text { Influencers can easily understand information about a } \\
\text { product or brand. }\end{array}$ & 0.457 & & & \\
\hline Influencers value the relationship with their followers. & 0.450 & & & \\
\hline Influencer has many followers or subscribers. & & 0.724 & & \\
\hline $\begin{array}{l}\text { Influencer makes good use of social networking } \\
\text { services (SNS). }\end{array}$ & & 0.662 & & \\
\hline Influencers have a ripple effect on public opinion. & & 0.658 & & \\
\hline Influencers themselves have a marketing effect. & & 0.609 & & \\
\hline Influencers have a great effect on the public. & & 0.587 & & \\
\hline
\end{tabular}


Table 3. Cont.

\begin{tabular}{|c|c|c|c|c|}
\hline \multirow{2}{*}{ Variable } & \multicolumn{4}{|c|}{ Factor } \\
\hline & (1) F1 & (2) F2 & (3) F3 & (4) F4 \\
\hline Influencers are now a man in the public eye. & & 0.567 & & \\
\hline Influencers have excellent content management skills & & 0.529 & & \\
\hline Influencers are well-known people in their field. & & 0.502 & & \\
\hline $\begin{array}{l}\text { Influencers provide quick feedback on the reactions of } \\
\text { followers and subscribers. }\end{array}$ & & 0.452 & & \\
\hline Influencers leads the trend. & & 0.428 & & \\
\hline $\begin{array}{l}\text { Influencers must communicate objective information } \\
\text { about a product or brand. }\end{array}$ & & & 0.888 & \\
\hline Influencers should be honest without lying. & & & 0.703 & \\
\hline Influencers must broadcast with sincerity. & & & 0.683 & \\
\hline Influencers must have clear beliefs and own philosophy. & & & 0.665 & \\
\hline $\begin{array}{l}\text { Influencers must speak and act politely when } \\
\text { communicating with consumers. }\end{array}$ & & & 0.649 & \\
\hline $\begin{array}{l}\text { Influencers must have consistent tone and manners such } \\
\text { as words, writing, and actions. }\end{array}$ & & & 0.538 & \\
\hline Influencers strive for self-development. & & & 0.522 & \\
\hline Influencers have excellent skills in their field. & & & & 0.668 \\
\hline Influencers have a passion for their work. & & & & 0.590 \\
\hline Influencers have their own special content. & & & & 0.568 \\
\hline Influencers have expertise in their field. & & & & 0.566 \\
\hline Influencers have fun and interest in their work. & & & & 0.501 \\
\hline $\begin{array}{l}\text { Influencers have their own personality } \\
\text { and characteristics. }\end{array}$ & & & & 0.491 \\
\hline $\begin{array}{c}\text { Influencers know their field well and have } \\
\text { accurate knowledge. }\end{array}$ & & & & 0.472 \\
\hline $\begin{array}{l}\text { Influencers must take responsibility for their own content } \\
\text { or words and actions. }\end{array}$ & & & & 0.464 \\
\hline $\begin{array}{l}\text { Influencers must fulfill their promises with } \\
\text { followers well. }\end{array}$ & & & & 0.449 \\
\hline Eigenvalue & 23.691 & 2.548 & 1.167 & 1.139 \\
\hline Variance explained (\%) & 54.232 & 5.103 & 1.894 & 1.787 \\
\hline Variance cumulated (\%) & 54.232 & 59.335 & 61.228 & 63.015 \\
\hline Cronbach's $\alpha$ & 0.930 & 0.937 & 0.926 & 0.924 \\
\hline
\end{tabular}

\subsection{Confirmatory Factorial Analysis}

To verify the validity of the four dimensions extracted in the EFA, we conducted a CFA that produced 27 items for the final four dimensions. Next, to verify the fit of the structural model, we calculated absolute fit index, parsimonious fit index, and incremental fit index. Among the many research criteria used to assess model fit, we chose a number that are typical:/df, root mean square error of approximation (RMSEA), adjusted goodness of fit index (AGFI), comparative fit index (CFI), and Tucker Lewis index (TLI). All of the fitness indices for our study data indicated good model fit: $\chi^{2} / \mathrm{df}=2.23$, RMSEA $=0.06$, AGFI $=0.81$, CFI $=0.93$, TLI $=0.92$ (see Table 4) $[97,98]$. 
Table 4. Model fit statistics.

\begin{tabular}{cccccc}
\hline Model & $\chi^{2} / \mathbf{d f}$ & RMSEA & AGFI & CFI & TLI \\
\hline Criterion & $<3$ & $<0.08$ & $>0.80$ & $>0.90$ & $>0.90$ \\
\hline Structural model & 2.23 & 0.06 & 0.81 & 0.93 & 0.92
\end{tabular}

Note: Root mean square error of approximation: RMSEA; adjusted goodness of fit index: AGFI; comparative fit index: CFI; Tucker Lewis index: TLI.

To review the construct validity, we used the CFA to calculate the construct reliability (CR) and the average variance extracted (AVE); generally, CR is considered reliable if it is 0.70 or higher, and AVE should be 0.50 or higher [99]. All CRs and AVEs met the criteria. We confirmed high correlation between the items that constituted each factor, which indicates convergent validity (see Table 5).

Table 5. Construct reliability (CR), Average variance extracted (AVE), and validity.

\begin{tabular}{|c|c|c|c|c|c|c|c|c|}
\hline & \multirow[b]{2}{*}{ Variables } & & \multicolumn{2}{|c|}{ Factor Loading } & \multirow[b]{2}{*}{$\mathrm{SE}$} & \multirow[b]{2}{*}{ CR } & \multirow[b]{2}{*}{ AVE } & \multirow[b]{2}{*}{ CR } \\
\hline & & & Estimate & $\begin{array}{l}\text { Standardized } \\
\text { Estimate }\end{array}$ & & & & \\
\hline \multirow{6}{*}{$\begin{array}{l}\text { Communication } \\
\text { Skills }\end{array}$} & $\rightarrow$ & Q1 & 1.000 & 0.730 & & & \multirow{6}{*}{0.540} & \multirow{6}{*}{0.876} \\
\hline & $\rightarrow$ & Q2 & 0.899 & 0.746 & 0.071 & 12.718 & & \\
\hline & $\rightarrow$ & Q3 & 1.170 & 0.724 & 0.095 & 12.317 & & \\
\hline & $\rightarrow$ & Q4 & 0.999 & 0.757 & 0.077 & 12.928 & & \\
\hline & $\rightarrow$ & Q5 & 1.100 & 0.713 & 0.091 & 12.118 & & \\
\hline & $\rightarrow$ & Q6 & 1.142 & 0.737 & 0.091 & 12.554 & & \\
\hline \multirow{7}{*}{ Influence } & $\rightarrow$ & Q7 & 1.000 & 0.762 & & & \multirow{7}{*}{0.537} & \multirow{7}{*}{0.890} \\
\hline & $\rightarrow$ & Q8 & 1.053 & 0.761 & 0.078 & 13.493 & & \\
\hline & $\rightarrow$ & Q9 & 0.918 & 0.707 & 0.074 & 12.389 & & \\
\hline & $\rightarrow$ & Q10 & 0.975 & 0.773 & 0.071 & 13.739 & & \\
\hline & $\rightarrow$ & Q11 & 1.035 & 0.740 & 0.079 & 13.049 & & \\
\hline & $\rightarrow$ & Q12 & 0.973 & 0.743 & 0.074 & 13.110 & & \\
\hline & $\rightarrow$ & Q13 & 0.822 & 0.633 & 0.075 & 10.928 & & \\
\hline \multirow{7}{*}{ Authenticity } & $\rightarrow$ & Q14 & 1.000 & 0.697 & & & \multirow{7}{*}{0.607} & \multirow{7}{*}{0.915} \\
\hline & $\rightarrow$ & Q15 & 1.216 & 0.808 & 0.095 & 12.838 & & \\
\hline & $\rightarrow$ & Q16 & 1.198 & 0.820 & 0.092 & 13.005 & & \\
\hline & $\rightarrow$ & Q17 & 1.155 & 0.774 & 0.094 & 12.319 & & \\
\hline & $\rightarrow$ & Q18 & 1.155 & 0.767 & 0.095 & 12.219 & & \\
\hline & $\rightarrow$ & Q19 & 1.490 & 0.817 & 0.115 & 12.960 & & \\
\hline & $\rightarrow$ & Q20 & 1.323 & 0.765 & 0.109 & 12.186 & & \\
\hline \multirow{7}{*}{ Expertise } & $\rightarrow$ & Q21 & 1.000 & 0.770 & & & \multirow{7}{*}{0.570} & \multirow{7}{*}{0.902} \\
\hline & $\rightarrow$ & Q22 & 0.675 & 0.730 & 0.052 & 13.029 & & \\
\hline & $\rightarrow$ & Q23 & 0.721 & 0.646 & 0.064 & 11.302 & & \\
\hline & $\rightarrow$ & Q24 & 0.760 & 0.775 & 0.054 & 13.980 & & \\
\hline & $\rightarrow$ & Q25 & 0.682 & 0.717 & 0.054 & 12.738 & & \\
\hline & $\rightarrow$ & Q26 & 0.803 & 0.834 & 0.053 & 15.299 & & \\
\hline & $\rightarrow$ & Q27 & 0.789 & 0.800 & 0.054 & 14.541 & & \\
\hline
\end{tabular}


Next, to verify the discriminant validity between the components of the social media influencer's reputation, we compared AVE, correlation coefficients $(\varphi)$, and squared correlation coefficients. If the AVE for each variable is greater than the squared value of all the correlation coefficients that contain the variable, the hypothesis is rejected that the correlation between the potential variables is equal $(\varphi=1.0)$. In other words, if $\varphi \pm 2 \times$ standard error is not 1 in the $95 \%$ confidence interval, it is reasonable to interpret a hypothesis to be supported [100]. The AVEs for all factors exceeded the squared correlation coefficients. In addition, because $\varphi \pm 2 \times$ standard error was not 1 in the $95 \%$ confidence interval of the correlation coefficients, there was exclusivity between the social media influencer's reputation constituents. We confirmed discriminant validity as Table 6 displays.

Table 6. Test of discriminant validity.

\begin{tabular}{ccccc}
\hline & Communication Skills & Influence & Authenticity & Expertise \\
\hline Communication Skills & $\mathbf{0 . 5 4 0}$ & 0.293 & 0.419 & 0.436 \\
\hline Influence & $\begin{array}{c}0.541^{* *} \\
(0.136)\end{array}$ & $\mathbf{0 . 5 3 7}$ & 0.153 & 0.329 \\
Authenticity & $\begin{array}{c}0.647^{* *} \\
(0.142)\end{array}$ & $\begin{array}{c}0.391^{* *} \\
(0.109)\end{array}$ & $\mathbf{0 . 6 0 7}$ & 0.397 \\
\hline Expertise & $\begin{array}{c}0.660^{* *} \\
(0.192)\end{array}$ & $\begin{array}{c}0.574^{* *} \\
(0.173)\end{array}$ & $\begin{array}{c}0.630^{* *} \\
(0.184)\end{array}$ & $\mathbf{0 . 5 7 0}$ \\
\hline
\end{tabular}

Note: ** $p<0.01$. bold text: AVE; bottom of bold text: correlation coefficient; top of bold text: squared correlation coefficient; ()$:(\varphi$ (correlation coefficient $) \pm 2 \times$ standard error $))$.

In summary, measurement items were refined further using two-step factor analysis. Factor analysis revealed the inclusion of 27 items: Six items for communication skills, seven items for influence, seven items for authenticity, and seven items for expertise. To assess the factor structure, this study used CFA, which indicated that the measures for social media reputation possessed reliable and valid factor structure.

\section{Discussion}

Influencers tends to influence many aspects including social, economic, and cultural areas. Especially, as a marketing communications strategy, social media influencers are effective and attract millions of customers around the world [18-20]. As influencers' effects have expanded, research interest has increased as well. Accordingly, many studies are being conducted, and the scope thereof is also diversifying. The scope ranges from the current influencer image displayed through social media activities to past activities in various fields and personal life. However, it is still regrettable that existing influencer studies are focused on their images and attributes [7,8,35-39]. Considering the current influencer's various activities and the effect of influencers on society, an evaluation limited to image does not have much meaning. From this point of view, this study aimed to develop items to measure a social media influencer's reputation as a new source of information in the SNS environment. However, in previous studies, no research has been presented to derive generalized measures for social media influencers' reputations. Therefore, through expert interviews and consumer surveys, 27 items for measuring social media influencers reputations were derived from four factors: Communication skills, influence, authenticity, and expertise. The results of this study are as follows.

The first factor was communication skills. In a digital environment, influencers are key to oral communication with consumers. Therefore, communication skills are a fundamental element that influencers must have in order to interact with consumers. It does not simply mean that you communicate well, but it means that you communicate your thoughts and feelings to consumers based on trust and communicate while sharing knowledge and information [43]. In particular, as influencers recently introduced and sold products through real-time video broadcasting, the communication skills of influencers are becoming more important. This commerce is live because the real-time communication 
between influencers and consumers has the largest advantages. Therefore, in order to persuade today's consumers, who are exposed to numerous messages and are negative about personal information exposure, influencers must interact with consumers through their communication skills. That is, it is important to understand what consumers really want through communication and empathize with them through communication rather than forcing consumers to listen information they do not want.

The second factor is influence. There is no specific criterion for judging the influence of influencers. Therefore, it is difficult to judge the influence or impact of influencers, simply based on the number of followers or activities. However, influencer content is delivered and spread to potentially millions of people in a short time through SNS. Therefore, an influencer's explanations, recommendations or criticisms about a particular product or brand affect the attitudes and behaviors of consumers [46,47,49]. From this point of view, influencers based on empathy, familiarity, and credibility can have a greater impact than traditional mass media. This is also why many companies use influencers as part of their marketing strategies [26-28]. In particular, as the marketing environment changes rapidly, influencers' influence is increasing to the extent that they threaten existing Internet shopping malls and TV home shopping, and influencers' influence is expected to increase further as they emerge as new distribution channels [26-28,101].

The third factor is authenticity. Authenticity has previously demonstrated considerable influence on celebrity reputation. Influencers induce direct consumer participation by providing the information consumers want [43]. Consumers have no rejection or negative perception of the information and evaluations provided by influencers who communicate with them on the network, and they trust and rely on their content. Information is perceived as if it was directly conveyed by acquaintances, and real experiences shared by influencers are accepted as genuine content. After all, authenticity is the strength of influencers over celebrities and is why consumers subscribe to influencer content. From a consumer's perspective, influencers appear to genuinely use the products and brands they talk about and to be communicating their candid opinions and assessments to consumers; this is why consumers feel familiarity with influencers, believe them to be credible, and believe their words and actions are authentic. However, to truly reach consumers, the emotional elements of authenticity and trustworthiness must be supported with practical knowledge. Popular influencers on TikTok recently uploaded an "Anti-Trump" video that omitted paid advertisements. After the BBC's report, TikTok deleted the content, but it caused negative controversy as it became known that influencers paid a certain amount of money from the marketing company to produce the video. This example shows why influencer authenticity is so important [102].

The fourth factor is expertise. In addition to communication skills, influence, and authenticity, we also identified expertise as a component of social media influencers' reputations. Expertise also had previously demonstrated considerable influence on celebrity reputation. It has become an environment where users can easily obtain information through SNS. In the past, consumers who used to depend only on mass media now search and share information on their own, making it easy for anyone to have expertise. Therefore, influencers with a lack of expertise not only cannot satisfy consumers, but they can also be ignored. From this point of view, influencers must support their credibility with knowledge, associating emotional elements with ability, and an influencer with expertise in specialized content can have a significant impact on consumer awareness and purchasing. This is because authenticity is possible only when the influencer has not only the emotional elements but also the ability. However, side effects are occurring recently due to the fact that some influencers are running shopping malls or businesses only with their own reputation and without specialized knowledge. Influencer Imvely from Korea found mold in pumpkin juice sold in online shopping malls, which caused controversy over the side effects of cosmetics sales and design plagiarism. Eventually, influencers lost consumer confidence and negatively affected sales [103]. In order to truly approach consumers from this point 
of view, the emotional component of authenticity and reliability must be supported by practical knowledge [48].

Next, we validated the dimensions and measurement items of the social media influencer's reputation. In this study, for validity verification, we verified that the convergent validity should be consistent among items measuring the same composition concept and for discriminant validity that there should be exclusivity between items measuring heterogeneous composition concepts. Convergence validity was verified as a high correlation among measurement items that measure the components of social media influencers' reputations such as communication skills, influence, authenticity, and expertise. In other words, it turns out that the items measured for each component had a high correlation with each other [99]. It was confirmed that there was discriminant validity due to the existence of exclusivity between social media influencer's reputation components. In other words, it was found that the variables used in this study were independently classified [100]. Through this, the reputation of social media influencers was characterized by a concept consisting of 27 measures in four dimensions: communication skills, influence, authenticity, and expertise.

Therefore, it can be said that the measures of a social media influencer's reputation, including the four dimensions of communication skills, influence, authenticity, expertise, displayed adequate construct reliability and validity. In addition, the statistical data all confirmed that the social media influencer's reputation items in this study can be used as consistent measurement tools for each factor. From this perspective, we established a theoretical foundation for social media influencers' reputations and verified practical findings, and by expanding the research scope of personal reputation, we lay the groundwork for future social media influencer's reputation research.

With the advancement of digital technology, we are living in an era of information explosion, newly created and distributed by the explosive growth of social media. In this environment, there is a growing demand for information monitoring and technology as suggested by the system proposed in Reference [104]. This information monitoring is the basis for effectively managing reputation. Hundreds of influencer contents are posted on social media every day, and influencers often post provocative titles to get their customer's attention. In this situation, the social media Influencer's Reputation score can serve as an indicator of the general quality of the influencer. Therefore, the social media Influencer's Reputation scale does not just collect accurate marketing-related information on its own, it helps you easily identify influencer content with integrity. The social media Influencer's Reputation scale has a variety of potential applications for consumers, influencers, and marketers and can serve as a theoretical framework for future empirical research in this new and emerging area. After all, reputation is critical to both companies, which need effective marketing, and influencers, who need profitability and sustainability.

\section{Conclusions and Limitations}

Although building and managing reputation is considered an important factor in the success of influencers, research on reputation in the context of influencers is lacking. Therefore, it makes sense to develop a multidimensional scale to assess the influencer's reputation. This study derived social media influencers' reputation measurement items and empirically verified the effectiveness of marketing communications targeting influencers whose influence was increasing due to the recent changes in the media communications environment. These findings suggest the following theoretical implications.

First, this study is meaningful in that we applied the concept of personal reputation, which has been widely discussed in previous studies, to social media influencers and validated items for use in measuring influencers' reputations. Influencer studies have been conducted in various fields, but existing studies have been limited in terms of influencer attributes and images. In particular, no previous researchers have presented generalized measurement items for influencer's reputation. We used the existing literature to identify potentially relevant measurement items and refined the items following expert interviews 
and consumer surveys to derive an accurate scale for measuring the construct. Second, the contribution of this study, therefore, lies in conceptualizing multidimensions of social media influencers' reputation and developing a reliable tool that measure these dimensions. This study was meaningful in that the research was conducted without prior research related to influencers' reputations and the importance of reputation was emphasized. From this perspective, we have built a theoretical foundation for influencer's reputation, validated practical findings, and expanded the research scope of personal reputation to lay the foundation for future social media influencer reputation research.

New platforms are constantly being released in the changing media environment, and consumers' media consumption patterns are changing accordingly. Existing social media platforms, such as YouTube and Instagram, are constantly introducing new functions or services to consumers. For consumers, these changes are simply a new way to communicate with brands, but for marketing practitioners, it means that the number of options to consider when choosing media continues to grow. Therefore, marketing practitioners are bound to be sensitive to social media trends, and it is paramount to see the latest trends. With this study, we intended to provide practical implications for incorporating influencers into marketing strategies.

First, the social media influencer's reputation dimensions and measurement items, derived from this study, are an effective tool for assessing the value of a particular influencer in a particular marketing campaign; marketing managers can determine the features that should be highlighted and target influencers who appear to possess the combination of reputation that might highlight those features. Second, the social media influencer's reputation scale aids influencers in managing their reputation. Influencers need to determine their evaluation of themselves through the reputation scale from their related stakeholders and strive to build a better reputation. They can strategically improve their overall reputation by emphasizing their strengths among the four different dimensions. Therefore, the findings are meaningful in that they provide a more systematic and strategic approach to managing social media influencers' reputations. Third, the social media influencer's reputation scale will also be useful for customers. Customers relied heavily on the reputation of influencer's opponents in the decision-making process. Therefore, these findings can be useful for designing influencer content on social media platforms. This is especially useful if reputation bias represents a factor that reduces the effectiveness of the system [105]. Therefore, the social media Influencer's Reputation scale can function as an indicator ensuring the general quality of the influencer content.

Notwithstanding the above conclusions, this study had some limitations that we discuss here, along with directions for future research. First, the surveys asked the respondents to respond on their own, recalling recent memories of influencers' SNS platforms they had visited. However, due to this being highly subjective, the respondents all thought of different influencers, and thus, the selection criteria were not completely controlled. To avoid errors, we suggest designating specific influencers based on research and collecting data on shared experiences and evaluations of the same set of influencers. We also propose that experimental research rather than surveys could give useful data. Second, the concept of influencer's reputation has many variables that can affect reputation, because it targets individuals, unlike traditional corporate reputation concepts. Items have been refined through three preliminary surveys, verification of the reliability and validity of survey questions, and expert reviews, but some items may have been excluded from the process. However, if research continues on influencers' reputations, we expect to build a more scientific and objective evaluation scale. In a follow-up study, it is necessary to establish a more scientific and objective evaluation scale in consideration of these areas. In addition, various follow-up studies on how the social media Influencer's Reputation scale derived through this study can be applied to the actual marketing environment are considered necessary. Third, the social media Influencer's Reputation scale extracted in this study was derived by considering only the situation in Korea, and it is questionable whether generalization is possible. Therefore, the social media Influencer's Reputation scale can 
derive a model of measurement of celebrity reputation, generalized standards, from a much larger sample than that conducted in this current study. That is, practical verification that can be applied to other countries is required, and through this, it is necessary to develop an objective measure that can be standardized globally.

Despite the existence of these limitations, this study is meaningful in that we derived components and measurement items of a social media influencer's reputation. At a time of great social and economic transformation, reputation management is an important value that should take priority. In particular, in an era when relationships are perceived to be important, consumers will think more about an influencer's reputation because companies are more focused on social value and sustainability. From this perspective, we hope that the results from this study will contribute both academically and practically to future research in influencer marketing communications.

Author Contributions: E.A.R. and E.H. conceived and designed the initial research idea; E.A.R. performed the literature review and analyzed the data; E.A.R. and E.H. wrote the paper. All authors have read and agreed to the published version of the manuscript.

Funding: This research received no external funding.

Institutional Review Board Statement: Because of the nature of this study, no formal approval of the Institutional Review Board of the local Ethics Committee was required. Nonetheless, all subjects were informed about the study and participation was fully on a voluntary basis. Participants were ensured of confidentiality and anonymity of the information associated with the surveys. The study was conducted according to the guidelines of the Declaration of Helsinki.

Informed Consent Statement: Informed consent was obtained from all subjects involved in the study.

Data Availability Statement: The data presented in this study are available on request from the corresponding author.

Conflicts of Interest: The authors declare no conflict of interest.

\section{References}

1. Choi, J.B. Phono Sapiens: Newcomers Born of Smartphones; Sam and Parkus: Seoul, Korea, 2019.

2. Belton, A. Social Influence: Leveraging the Power of Influencers to Build Brand Advocacy. Available online: https://www.ana.net/ blogs/show/id/mm-blog-2018-12-leveraging-the-power-of-influencers-to-build-brand-advocacy (accessed on 8 January 2019).

3. Mediakix. Why the Influencer Marketing Industry Will Be a \$5-\$10-Billion-Dollar Market in the Next 5 Years. Available online: https://mediakix.com/blog/influencer-marketing-industry-ad-spend-chart/ (accessed on 6 March 2018).

4. KOTRA. Strategies to Enter the U.S.; Market with Social Network Influencer: Seoul, Korea, 2017; Available online: http:// openknowledge.kotra.or.kr/handle/2014.oak/9997 (accessed on 15 September 2017).

5. Voorveld, H.A.M.; Van Noort, G.; Mutinga, D.G.; Bronner, F. Engagement with social media and social media advertising: The differentiation role of platform type. J. Advert. 2018, 47, 38-54. [CrossRef]

6. Abidin, C. Visibility labour: Engaging with influencers' fashion brands and \#OOTD advertorial campaigns on Instagram. Media Int. Aust. 2016, 161, 86-100.

7. De Veirman, M.; Cauberghe, V.; Hudders, L. Marketing through Instagram influencers: The impact of number of followers and product divergence on brand attitude. Int. J. Advert. 2017, 36, 798-828. [CrossRef]

8. Djafarova, E.; Rushworth, C. Exploring the credibility of online celebrities' Instagram profiles in influencing the purchase decisions of young female users. Comput. Hum. Behav. 2017, 68, 1-7. [CrossRef]

9. Haugtvedt, C.P.; Machleit, K.A.; Yalch, R. Online Consumer Psychology: Understanding and Influencing Consumer Behavior in the Virtual World; Psychology Press: New York, NY, USA, 2005.

10. Amato, F.; Moscato, V.; Picariello, A.; Sperlí, G. Multimedia social network modeling: A proposal. In Proceedings of the 2016 IEEE Tenth International Conference on IEEE Semantic Computing (ICSC), Laguna Hills, CA, USA, 3-5 February 2016 ; pp. $448-453$.

11. Seoul Economy. Available online: https://m.sedaily.com/NewsView/1VJ9N60EGH/GF01\#cb (accessed on 24 May 2019).

12. Tetsuya Honda. Influencer Marketing; Management Spirit: Seoul, Korea, 2008.

13. Bohan, J. Influencer Marketing Is a Content and Distribution Two for One. Available online: https://www.forbes.com/sites/ forbesagencycouncil/2016/11/07/influencer-marketing-is-a-content-and-distribution-two-for-one/ (accessed on 7 November 2016).

14. Foster, J. Steps to Executing a Flawless Influencer Marketing Campaign. 2015. Available online: https://blog.marketo.com/2015 /05/3-steps-to-executing-a-flawless-influencer-marketing-campaign.html (accessed on 5 September 2019).

15. McQuarrie, E.F.; Miller, J.; Phillips, B.J. The megaphone effect: Taste and audience in fashion blogging. J. Consum. Res. 2013, 40, 136-158. [CrossRef] 
16. Jim, T. Influencer Marketing is under Attack: Six Reasons It Still Works. Available online: https://www.forbes.com/ sites/forbesagencycouncil/2018/06/01/influencer-marketing-is-under-attack-six-reasons-it-still-works/?sh=d36a4e160588 (accessed on 1 June 2018).

17. Van den Bulte, C.; Joshi, Y.V. New product diffusion with influentials and imitators. Mark. Sci. 2007, 26, 1-23. [CrossRef]

18. Harrison, K. Top 10 trends that will transform digital marketing in 2017. Available online: https://www.forbes.com/sites/ kateharrison/2017/01/09/top-10-trends-that-will-transform-digital-marketing-in-2017/?sh=48b128d73bf5 (accessed on 9 January 2017).

19. Phua, J.J.; Jin, S.A.; Kim, J.H. Gratifications of using Facebook, Twitter, Instagram, or snapchat to follow brands: The moderating effect of social comparison, trust, tie strength, and network homophily on brand identification, brand engagement, brand commitment, and membership intention. Telemat. Inf. 2016, 34, 412-424. [CrossRef]

20. Talaverna, M. 10 Reasons Why Influencer Marketing Is the next Big Thing. Available online: https://www.adweek.com/digital/ 10-reasons-why-influencer-marketing-is-the-next-big-thing/ (accessed on 14 July 2015).

21. eMarketer. Influencer Marketing Roundup. Available online: https://www.emarketer.com/content/influencer-marketingroundup-2018 (accessed on 8 August 2018).

22. Evans, N.J.; Phua, J.; Lim, J.; Jun, H. Disclosing Instagram influencer advertising: The effects of disclosure language on advertising recognition, attitudes, and behavioral intent. J. Interact. Advert. 2017, 17, 138-149. [CrossRef]

23. Li, Z. Psychological empowerment on social media: Who are the empowered users? Public Relat. Rev. 2016, 42, 49-59. [CrossRef]

24. Ong, Y.X.; Ito, N. I want to go there too! Evaluating social media influencer marketing effectiveness: A case study of Hokkaido's DMO. In Information and Communication Technologies in Tourism; 2019; pp. 132-144. Available online: http:/ /link-springer-com-44 3.webvpn.fjmu.edu.cn/chapter/10.1007\%2F978-3-030-05940-8_11 (accessed on 15 December 2018).

25. Ramadan, R. Questioning the role of Facebook in maintaining Syrian social capital during the Syrian crisis. Heliyon 2017, 3, e00483. [CrossRef] [PubMed]

26. Booth, N.; Matic, J.A. Mapping and leveraging influencer in social media to shape corporate brand perceptions. Corp. Commun. Int. 2011, 16, 184-191. [CrossRef]

27. Ge, J.; Gretzel, U. Emoji rhetoric: A social media influencer perspective. J. Mark. Manag. 2018, 34, 1272-1295. [CrossRef]

28. Fertik, M. Why is Influencer Marketing Such A Big Deal Right Now? Available online: https://www.forbes.com/sites/michaelfertik/ 2020/07/02/why-is-influencer-marketing-such-a-big-deal-right-now/?sh=7c70e88d75f3\#5be7c9d375f3 (accessed on 2 July 2020).

29. Balmer, J.M.T. Corporate identity and the advent of corporate marketing. J. Mark. Manag. 1998, 14, 963-996. [CrossRef]

30. Gotsi, M.; Wilson, A.M. Corporate reputation: Seeking a definition. Corporate Communications. Int. J. 2001, 6, 24-30. [CrossRef]

31. Rayner, J. Managing Reputational Risk: Curbing Threats, Leveraging Opportunities; John Wiley \& Sons: Hoboken, NJ, USA, 2003.

32. Tucker, L.; Melewar, T.C. Corporate reputation and crisis management: The threat and manageability of anti-corporatism. Corp. Reput. Rev. 2005, 7, 377-387. [CrossRef]

33. Balmer, J.M.T. Corporate Identity: Past, Present and Future; Working Paper; Department of Marketing, University of Strathclyde: Glasgow, Scotland, 1997.

34. Fombrun, C.J.; Rindova, V. The Road to Transparency: Reputation Management at Royal Dutch/Shell; Oxford University Press: Oxford, $\mathrm{UK}, 2000$.

35. DeCremer, D.; Sedikides, C. Reputational implications of procedural fairness for personal and relational self-esteem. Basic Appl. Soc. Psychol. 2008, 30, 66-75. [CrossRef]

36. Ekstam, V.; Bjurling, L. Influencer Marketing's Effect on Brand Perceptions: A Consumer Involvement Perspective. Master's Thesis, Lund University, Lund, Sweden, 2018.

37. Lee, J.E.; Watkins, B. YouTube vloggers' influence on consumer luxury brand perceptions and intentions. J. Bus. Res. 2016, 69, 5753-5760. [CrossRef]

38. Sofi, S.A.; Naja, S.A. Impact of personality influencers on psychological paradigms: An empirical discourse of big five framework and impulsive buying behavior. Eur. Res. Manag. Bus. Econ. 2017, 24, 71-81. [CrossRef]

39. Tanase, R.; Tessone, C.J.; Algesheimer, R. Identification of influencer through the wisdom of crowds. PLoS ONE 2018, 13, e0200109. [CrossRef]

40. Wiedmann, K.; Hennings, N.; Langner, S. Spreading the word of fashion: Identifying social influencer in fashion marketing. J. Glob. Fash. Mark. 2010, 1, 142-153. [CrossRef]

41. Blackwell, R.D.; Miniard, P.W.; Engel, J.F. (Eds.) Consumer Behavior; Dryden Press: Fort Worth, TX, USA, 2001.

42. Khamis, S.; Ang, L.; Welling, R. Self-branding, 'micro-celebrity' and the rise of social media influencer. Celebr. Stud. 2017, 8, 191-208. [CrossRef]

43. Choi, J.Y.; Jung, Y.J. The Study on the Strategies of Beauty Influencer Marketing: Mass Media vs. Social Media. Korean. J. Advert. 2017, 28, 47-72. [CrossRef]

44. Swant, M. Twitter Says Users Now Trust Influencer Nearly Much Their Friends. Available online: https://www.adweek.com/ digital/twitter-says-users-now-trust-influencers-nearly-much-their-friends171367/ (accessed on 10 May 2016).

45. Godey, B.; Manthiou, A.; Pederzoli, D.; Rokka, J.; Aiello, G.; Donvito, R.; Singh, R. Social media marketing efforts of luxury brands: Influence on brand equity and consumer behavior. J. Bus. Res. 2016, 69, 5833-5841. [CrossRef]

46. Liu, S.; Jiang, C.; Lin, Z.; Ding, Y.; Duan, R.; Xu, Z. Identifying effective influencer based on trust for electronic wom marketing: A domain aware approach. Inf. Sci. 2015, 306, 34-52. [CrossRef] 
47. Sudha, M.; Sheena, K. Impact of influencers in consumer decision process: The fashion industry. SCMS J. Indian. Manag. 2017, 14, 14-30.

48. Kim, W.B.; Choo, H.J. Impact of sincerity on consumer behavior in SNS fashion influencer: The mediated effect of influencer's fANSHIP. Korean Soc. Cloth. Text. 2017, 13, 17-32.

49. Hong, D.H.; Jeon, J.W. MCN (Multi Channel Network's Branded Entertainment Content Effectiveness. Korean Acad. Soc. Public Relat. 2016, 20, 171-194.

50. Fombrun, C.J. Reputation: Realizing Value from the Corporate Image; Harvard Business School Press: Boston, MA, USA, 1996.

51. Hall, R. The strategic analysis of intangible resources. Strateg. Manag. J. 1992, 13, 135-144. [CrossRef]

52. Fine, G.A. Difficult Reputations: Collective Memories of the Evil, Inept, and Controversial; University of Chicago Press: Chicago, IL, USA, 2001.

53. Rein, G.L. A reference model for designing effective reputation information systems. J. Inf. Sci. 2005, 31, 365-380. [CrossRef]

54. Whitmeyer, J.M. Effects of positive reputation systems. Soc. Sci. Res. 2000, 29, 188-207. [CrossRef]

55. Miller, G.D. Hypothesis on reputation: Alliance choices and the shadow of the past. Secur. Study 2003, 12, 40-78.

56. Han, E.K.; Lee, B.Y.; Moon, H.J. A Study on the Effectiveness Model of Corporate Reputation and CEO Reputation: Focused on Samsung and SK. Korean. J. Advert. 2007, 16, 125-144.

57. Fombrun, C.J.; Shanley, M. What's in a name? Reputation building and corporate strategy. Acad. Manag. J. 1990, 33, $233-258$.

58. Karen, C.; Elizabeth, G.O.; Sridhar, R. The Reputation Index; Measuring and Managing Corporate Reputation. Eur. Manag. J. 2003, 21, 201-212.

59. Roberts, P.W.; Dowling, G.R. Corporate reputation and sustained superior financial performance. Strat. Manag. J. 2002, 23, 1077-1093. [CrossRef]

60. Schwaiger, M. Components and parameters of corporate reputation: An empirical study. Schmalenbach Bus. Rev. 2004, 56, 46-71. [CrossRef]

61. Han, E.K.; Moon, H.J.; Hwang, G.S.; Ryu, E.A.; Yoo, H.S.; Kim, J.; Kim, I.; Lee, Y.J.; Byun, Y.W.; Shim, I.; et al. Brand Reputation Innovation Design; Nanam: Seoul, Korea, 2020.

62. Zinko, R.; Ferris, G.R.; Humphrey, S.E.; Meyer, C.J.; Aime, F. Personal reputation in organizations: Two-study constructive replication and extension of antecedents and consequences. J. Occup. Organ. Psychol. 2012, 85, 156-180. [CrossRef]

63. Carter, J.; Bitting, E.; Ghorbani, A.A. Reputation formalization within information sharing multiagent architectures. Comput. Intell. 2002, 18, 515-534. [CrossRef]

64. Fombrun, C.J.; Van Riel, C.B.M. Fame and Fortune: How Successful Companies Build Winning Reputations; Prentice Hall: Upper Saddle, NJ, USA, 2003.

65. McGuire, W.J. Attitudes and attitude change. In Handbook of Social Psychology, 3rd ed.; Lindzey, G., Aronson, E., Eds.; Random House: New York, NY, USA, 1985; Volume 2, pp. 233-346.

66. Ohanian, R. The impact of celebrity spoke person's perceived image on consumers' intention to purchase. J. Advert. Res. 1991, 31, 46-54.

67. Belch, G.E.; Belch, M.A. (Eds.) Introduction to Advertising and Promotion: An Integrated Marketing Communications Perspective; Irwin: Chicago, IL, USA, 1994.

68. Erdogan, B.Z.; Baker, M.J.; Tagg, S. Selecting celebrity endorsers: The practitioner's perspective. J. Advert. Res. 2001, 41, 39-48. [CrossRef]

69. Hovland, C.I.; Janis, I.L.; Kelley, H.H. Communication and Persuasion; Psychological Studies of Opinion Change; Yale University Press: New Haven, GT, USA, 1953.

70. Belch, G.E.; Belch, M.A. (Eds.) Advertising and Promotion: An Integrated Marketing Communication Perspective; McGraw-Hill: New York, NY, USA, 2001.

71. McCracken, G. Who is the celebrity endorser? Cultural foundations of the endorsement process. J. Consum. Res. 1989, 16, 310-321.

72. McGuire, W.J. Persuasion, resistance, and attitude change. In Handbook of Communications; Pool, I., Schramm, W., Frey, F., Maccoby, N., Parker, E.B., Eds.; Rand McNally: Chicago, IL, USA, 1973; pp. 216-252.

73. Debevec, K.; Kernan, J.B. More evidence on the effects of a preventer's physical attractiveness: Some cognitive, affective and behavioral consequence. Adv. Consum. Res. 1984, 11, 127-132.

74. Goldsmith, R.E.; Lafferty, B.A.; Newell, S.J. The impact of corporate credibility and celebrity credibility on consumer reaction to advertisements and brands. J. Advert. 2000, 24, 43-54. [CrossRef]

75. McDonald, W.J. Home shopping channel customer segments: A cross-cultural perspective. J. Direct. Mark. 1995, 9, 57-67. [CrossRef]

76. Atkin, C.; Block, M. Effectiveness of celebrity endorsers. J. Advert. Res. 1983, 23, 57-61.

77. Basil, M.D. Identification as a mediator of celebrity effects. J. Broadcasting. Electron. Media 1996, 40, 478-495. [CrossRef]

78. Kamins, M.A. Celebrity and noncelebrity advertising in a two-sided context. J. Advert. Res. 1989, $29,34-42$.

79. Batool, S.; Malik, N.I. Role of attitude similarity and proximity in interpersonal attraction among friends. Int. J. Innov. Technol. 2010, 1, 142-146.

80. Sampson, E. First impressions: The power of personal style. Libr. Manag. 1995, 16, 25-28. [CrossRef]

81. Gaines-Ross, L. CEO Reputation: A key factor in shareholder value. Corp. Reput. Rev. 2000, 3, 366-370. [CrossRef]

82. Garbet, T. How to Build a Corporation's Identity and Project Its Image; Lexington Books: Lexington, MA, USA, 1988. 
83. Han, E.K.; Yoo, J.H. A Study on the Measurement of Korean Wave's Human Brand Equity; Korea Broadcast Advertising Corporation: Seoul, Korea, 2005.

84. Oh, Y.K.; Lee, K.H. Study on the Type Analysis and Image of the Personal Style-Focused on Korean Female Entertainers. J. Korean Soc. Cloth. Text. 2006, 30, 137-145.

85. Baker, M.J.; Churchill, G.A. The impact of physically attractive models on advertising evaluations. J. Mark. Res. 1977, 14, 538-555. [CrossRef]

86. Kitchen, P.J.; Laurence, A. Corporate reputation: An eight-country analysis. Corp. Reput. Rev. 2003, 6, 103-117. [CrossRef]

87. Zorn, T. Talking heads: The CEO as spokesperson. In Raising the Corporate Umbrella: Corporate Communication in the 21st Century; Kitchen, P.J., Schultz, D.E., Eds.; Palgrave: Basingstoke, UK, 2001; pp. 23-42.

88. Lewis, F.D. Race and Para-Social Interaction in a Television Situation Comedy. Ph.D. Thesis, University of Kentucky, Lexington, KY, USA, 2000.

89. Mondy, R.W.; Premeaux, S.R. Management Concepts, Practices and Skills; Prentice-Hall Inc.: Englewood Cliffs, NJ, USA, 1995.

90. Burson-Marsteller Report. CEO Reputation Study. Available online: https://issuu.com/burson-marsteller-emea/docs/ceoreport (accessed on 25 May 2010).

91. Han, E.K.; Kim, Y.H.; Moon, H.J. A Study on the Effect Model of the Corporate Reputation and the CEO Reputation: With Focus on Samsung and SK. Korean J. Advert. 2005, 16, 125-144.

92. Ahn, J.H. Study of Sports Athlete Reputation and Sponsorship: Focused on Measuring Professional Golfers' Reputation Index Ph.D. Thesis, University of Sungkyunkwan, Seoul, Korea, 2012.

93. Lee, B.Y. A Study on the Influence of the Reputation of Entertainers upon the Attribution Disposition of the Public. Ph.D. Thesis, University of Sungkyunkwan, Seoul, Korea, 2006.

94. Hair, J.F.; Black, W.C.; Babin, B.J.; Anderson, R.E.; Tatham, R.L. Multivariate Data Analysis; Prentice Hall: Upper Saddle River, NJ, USA, 1998

95. Kaiser, H.F. The application of electronic computers to factor analysis. Educ. Psychol. Meas. 1960, 20, 141-151. [CrossRef]

96. Crocker, L.; Algina, J. Introduction to Classical and Modern Test Theory; Harcourt: New York, NY, USA, 1986.

97. Browne, M.W.; Cudeck, R. Alternative ways of assessing model fit. In Testing Structural Equation Models; Bollen, K.A., Long, J.S., Eds.; Sage: Newbury Park, CA, USA, 1993; pp. 136-162.

98. Tucker, L.R.; Lewis, C. A reliability coefficient for maximum likelihood factor analysis. Psychometrika 1973, 38, 1-10. [CrossRef]

99. Anderson, J.C.; Gerbing, D.W. Structural equation modeling in practice: A review and recommended two-step approach. Psychol. Bull. 1988, 103, 411-423. [CrossRef]

100. Fornell, C.; Larcker, D.F. Evaluating structural equation models with unobservable variables and measurement error. J. Mark. Res. 1981, 18, 39-50. [CrossRef]

101. Joongangilbo. Available online: https://news.joins.com/article/23875652 (accessed on 19 September 2020).

102. BBC NEWS. Available online: https:/ / www.bbc.com/korean/international-54615796 (accessed on 19 October 2020).

103. Edaily. Available online: https: / / www.edaily.co.kr/news / read?newsId=01397286625804344\&mediaCodeNo=E (accessed on 22 June 2020).

104. Amato, F.; Moscato, V.; Picariello, A.; Sperlí, G. Kira: A system for knowledge-based access to multimedia art collections. In Proceedings of the 2017 IEEE 11th International Conference on Semantic Computing, San Diego, CA, USA, 30 January1 February 2017; pp. 338-343.

105. Amato, F.; Moscato, V.; Picariello, A.; Sperlí, G. Diffusion Algorithms in Multimedia Social Networks: A preliminary model. In Proceedings of the 2017 IEEE/ACM International Conference on Advances in Social Networks Analysis and Mining 2017, Sydney, Australia, 31 July-3 August 2017; pp. 844-851. 